\title{
Determination of the optimal option for production of the convex cost function
}

\author{
Rima Petrosyan $^{1 *}$, and Alexander Mailyan ${ }^{2}$ \\ ${ }^{1}$ Moscow State University of Civil Engineering, 26 Yaroslavskoe shosse, Moscow, 129337, Russia \\ ${ }^{2}$ Don State Technical University, 1 Gagarin square, Rostov-on-Don, 344000, Russia
}

\begin{abstract}
The choice of the optimal option for the production of in the construction of buildings and structures is based on a preliminary generalization and analysis of the most promising options for the implementation of construction and installation from which the most rational optimal in the is selected conditions under consideration. The purpose of the study is to determine the optimal option for production of at the convex cost function. We used the method of the determination of costs on the duration of works, represented by a convex function showing the shorter the duration of the project the more costs are required when it is reduced by the same amount. The key parameters affecting the final result of construction are the duration cost and quality of performed. Consequently, one of the main tasks is to draw up a works schedule with close coordination of the resources necessary for their implementation. To do this we have to solve problems associated with the distribution of limited resources. In this case, the technological interdependence between the works performed, which may be of a different nature, should be taken into account. As the results, new approaches were founded to developing a strategy for the selection of options for construction and installation works in order to ensure contractual deadlines for their implementation and minimize the funds spent on their implementation taking into account the nature of the dependencies between the works performed is an urgent and important problem.
\end{abstract}

\section{Introduction}

Construction production is multivariate in nature that is each works can be performed in several ways both from the point of view of technology and from the point of view of the organization of its implementation [1]. Existing models for the selection of organizational and technological solutions for the implementation of construction and installation are mainly aimed at ensuring that the resources attracted by the construction organization meet the requirements dictated by the works performed and at choosing the most rational scheme for the movement of construction crews on construction sites that will help to reduce the construction time. $[2,3]$

* Corresponding author: PetrosyanRS@mgsu.ru 
In cases when it comes to the implementation of construction and installation at one facility the relationships between the jobs are unchanged and their violation is impossible or involves very high costs [4]. If construction and installation are carried out at various facilities, the relationships between such are advisory in nature and their violation is possible but leads to additional costs. The effectiveness of these costs must be established at the stage of organizational and technological design. [5-7]

A construction organization usually performs works simultaneously on a number of construction sites and the nomenclature of such construction sites is constantly changing and the organization's activities must ensure that the works is completed within the time specified by contractual obligations [9-11]. Considering that the reduction of the terms of the works can be achieved under constant production and technological conditions (with constant technical equipment and a given level of labor productivity) only due to the saturation of additional resources or due to the combined execution of works it is obvious that the desire of the enterprise to meet the contractual deadlines works often leads to additional costs. In this regard the problem arises of choosing options for the production of at the facilities arises so that if the contractual deadlines are met the minimum necessary amount of additional financial resources would be provided. [12-15]

\section{Materials and methods}

The dependence of costs on the duration of works [16] can be represented by a convex function showing the shorter the duration of the project the more costs are required when it is reduced by the same amount. In the particular case when the amount of reduction in the duration of any works [17] is a multiple of a certain number $\Delta$ (that is, the duration of works can be reduced by $\Delta, 2 \Delta, 3 \Delta$ etc.) without loss of generality constraint we can accept $\Delta$ equal to 1 (Fig. 1 ).

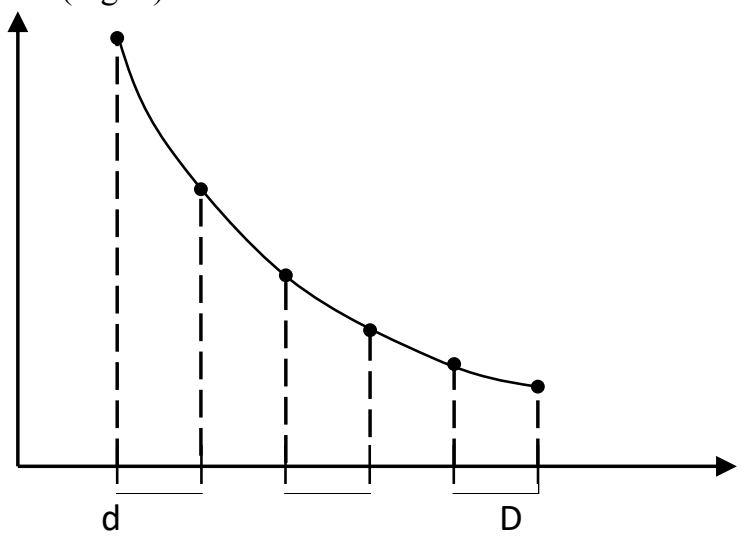

Fig. 1. Cost function

When connecting discrete points on the graph of the function by line segments we obtain a continuous piecewise-linear function of convex shape. We replace the discrete dependencies of costs on the duration of the works with the obtained continuous 
dependencies. Since as a rule the duration of the project is an integer there is always an integer solution to the problem of minimizing costs that is, a solution in which the duration of all works is an integer.

The noted property allows us to efficiently solve cost optimization problems for sequential and parallel sets of jobs [18] like convex programming problems. This is especially true of the minimization problem for a sequential set of jobs which in the discrete case is a difficult discrete optimization problem. [19]

Algorithms for solving cost minimization problems for sequential and parallel sets of jobs in the convex case are given below.

The dependence of costs on the duration of the $\mathrm{i}$ - works [20] is conveniently presented in the form of a table. 1. Its upper line contains the possible duration of works from a minimum of 4 to standard 9 and the bottom line shows the increment of costs $\mathbf{K}_{\mathbf{i}}$ when the duration is reduced by one with the exception of the rightmost number which is equal to the norm effective costs with a standard duration.

Table 1. The dependence of costs on the duration of the $\mathrm{i}$ - works

\begin{tabular}{|l|l|l|l|l|l|l|}
\hline$\tau_{\mathrm{i}}$ & 4 & 5 & 6 & 7 & 8 & 9 \\
\hline $\mathrm{K}_{\mathrm{i}}$ & 3 & 3 & 2 & 2 & 1 & 4 \\
\hline
\end{tabular}

To obtain the cost value for a given duration $\tau_{\mathrm{i}}$ it is enough to add all the numbers $\mathrm{K}_{\mathrm{i}}$ bottom line from $\tau_{\mathrm{i}}$ up to standard duration $\mathrm{D}_{\mathrm{i}}$. For example the costs of $\tau_{\mathrm{i}}=7$ are equal $\mathrm{S}(7)=2+$ $1+4=7$.

Parallel set of. Let be $d_{i} \leq \tau_{i} \leq D_{i}$, where $D_{i}$ - standard duration, di - minimum duration. It is obvious that the duration $\mathrm{T}$ of the parallel set of lies within

$$
\max _{\mathrm{i}} \mathrm{d}_{\mathrm{i}} \leq \mathrm{T} \leq \min _{\mathrm{i}} \mathrm{D}_{\mathrm{i}}
$$

For a given $T$, we determine the costs $S_{i}(T)$ for each works as described above and summarize them. This amount determines the minimum costs with a duration of no more than $T$.

Consistent set of works. Obviously the duration of a sequential set of works lies within

$$
\mathrm{d}=\sum_{\mathrm{i}} \mathrm{d}_{\mathrm{i}} \leq \mathrm{T} \leq \sum_{\mathrm{i}} \mathrm{D}_{\mathrm{i}}=\mathrm{D}
$$

where $\mathrm{D}$ is the standard duration of a sequential set of. To describe the algorithm for solving the problem for a sequential set of first we illustrate it with an example.

We have $10=1+2+3+4 \leq T \leq 4+5+6+7=22$.

\section{Results and discussion}

We use the proposed algorithm to solve the problems of organizational and technological design.

Example 1

We take the number of equal to 4 . The source data are given in table.2.

Table 2. Cost dependency for a given duration of work

\begin{tabular}{|l|l|l|l|l|l|l|l|l|}
\hline$\tau_{\mathrm{i}}$ & 1 & 2 & 3 & 4 & 5 & 6 & 7 & 8 \\
\hline $\mathrm{K}_{1}$ & 2 & 1 & 1 & 4 & & & & \\
\hline $\mathrm{K}_{2}$ & & 3 & 3 & 2 & 1 & & & \\
\hline $\mathrm{K}_{3}$ & & & 4 & 4 & 3 & 6 & & \\
\hline
\end{tabular}




\begin{tabular}{|l|l|l|l|l|l|l|l|l|}
\hline $\mathrm{K}_{4}$ & & & & 5 & 5 & 2 & 3 & \\
\hline
\end{tabular}

Let be $T=15$ that is, it is required to reduce the duration of the work package by $22-$ $15=7$ units. To do this, moving from right to left in the table. 2 we select 7 smallest $K_{i}$ numbers. Note that the number $K_{i}=1$ equally 2 , number $K_{i} \leq 2$ equally 5 , a number $K_{i} \leq 3$ equally 8 . Therefore we select 7 numbers $K_{i} \leq 3$. Two options are possible.

In the first version $\tau_{1}=1, \tau_{2}=3, \tau_{3}=5, \tau_{4}=6, \mathrm{~T}=15$

costly $\mathrm{S}_{1}+\mathrm{S}_{2}+\mathrm{S}_{3}+\mathrm{S}_{4}=8+6+9+5=28$.

In the second option $\tau_{1}=1, \tau_{2}=2, \tau_{3}=6, \tau_{4}=6, \mathrm{~T}=15$

at the same costs $\mathrm{S}_{1}+\mathrm{S}_{2}+\mathrm{S}_{3}+\mathrm{S}_{4}=8+6+9+5=28$.

Thus to obtain the optimal solution it is necessary to select $(D-T)$ the smallest $K_{i}$ coefficients, the selected coefficients determine the duration of works and the costs accordingly. As can be seen from the description both algorithms can effectively solve the problem of minimizing costs for sequential and parallel sets of works. Since these two tasks are the main ones in the algorithm for solving the general problem of minimizing costs the efficiency of the algorithm also increases [20].

Example 2

Consider the network diagram (Fig. 2).

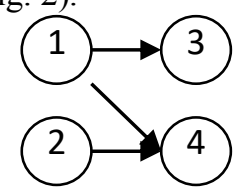

Fig.2. Network diagram

Figure 3 shows the converted aggregated network diagram and figure 4 shows us aggregation tree.

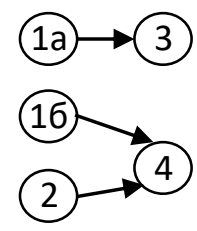

Fig.3. Converted aggregated network diagram

Data on the work are given in tables 3-7.

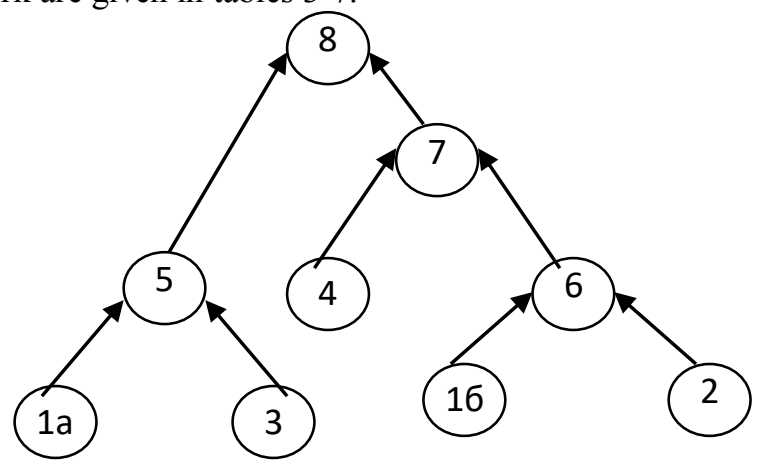

Fig.4. Aggregation tree

Table 3. Cost dependency for a given duration of work

\begin{tabular}{|c|c|c|c|c|c|c|c|c|}
\hline$\tau_{\mathrm{i}}$ & 1 & 2 & 3 & 4 & 5 & 6 & 7 & 8 \\
\hline $\mathrm{K}_{1 \mathrm{a}}$ & & 3 & 2 & 5 & & & & \\
\hline
\end{tabular}




\begin{tabular}{|c|c|c|c|c|c|c|c|c|}
\hline $\mathrm{K}_{1 \sigma}$ & & 3 & 2 & 5 & & & & \\
\hline $\mathrm{K}_{2}$ & 2 & 1 & 3 & & & & & \\
\hline $\mathrm{K}_{3}$ & & & 4 & 3 & 3 & & & \\
\hline $\mathrm{K}_{4}$ & & & 5 & 3 & 2 & & & \\
\hline
\end{tabular}

Step 1: Build a table for aggregated work 5. We have data of table 4.

Table 4. Cost dependency for a given duration of work 5

\begin{tabular}{|c|c|c|c|c|c|}
\hline$\tau_{5}$ & 9 & 8 & 7 & 6 & 5 \\
\hline $\mathrm{S}_{5}$ & 8 & 10 & 13 & 16 & 20 \\
\hline
\end{tabular}

Step 2: Build a table for aggregated work 6 . We have data of table 5.

Table 5. Cost dependency for a given duration of work 6

\begin{tabular}{|c|c|c|c|}
\hline$\tau_{6}$ & 4 & 3 & 2 \\
\hline $\mathrm{S}_{6}$ & 8 & 140 & 14 \\
\hline
\end{tabular}

Step 3: Build a table for aggregated work 7. We have data of table 6.

Table 6. Cost dependency for a given duration of work 7

\begin{tabular}{|c|c|c|c|c|c|}
\hline$\tau_{7}$ & 9 & 8 & 7 & 6 & 5 \\
\hline $\mathrm{S}_{7}$ & 10 & 12 & 15 & 19 & 24 \\
\hline
\end{tabular}

Step 4: Build a table for aggregated work 8. We have data of table 7.

Table 7. Cost dependency for a given duration of work 8

\begin{tabular}{|c|c|c|c|c|c|}
\hline$\tau_{8}$ & 9 & 8 & 7 & 6 & 5 \\
\hline $\mathrm{S}_{8}$ & 18 & 22 & 28 & 35 & 44 \\
\hline
\end{tabular}

We construct a parametric dependence of costs on the duration of the project:

1. $\mathrm{T}=9, \mathrm{~S}=18$. All work is performed with a standard duration.

2. $\mathrm{T}=8, \mathrm{~S}=22$. Work $1 \mathrm{a}$ is performed with duration of step 3 , work $1 \mathrm{~b}$ is also with duration of step 3 , the rest of the work with a standard duration.

3. $\mathrm{T}=7, \mathrm{~S}=28$. Work 4 is performed with duration of step 4 , work 3 also with duration of step 4 .

4. $\mathrm{T}=6, \mathrm{~S}=35$. Work 1 is performed with a minimum duration of step 2 , work 2 with duration of step 2, work 3 and 4 with duration of step 4 .

5. $\mathrm{T}=5, \mathrm{~S}=44$. All work is performed with a minimum duration with the exception of work 2 which is performed with duration of 2 .

In this example in all cases solving the transformed problem - for the aggregated network — gives an acceptable solution to the original problem.

\section{Conclusions}

A model is proposed for the selection of options for the production of construction and installation works with a minimum of funds allocated to reduce the time for their implementation which differs by taking into account the technological sequence of the work and allows you to get a plan that can be implemented with minimal costs. 
The model for choosing options for the production of works [21], taking into account the property of convexity of the cost function, makes it possible to significantly simplify the procedure for obtaining a solution.

The developed models allow selecting options for the production of works that minimize the additional funds allocated to reduce the time required to complete the work when the contractual terms for the erection of construction projects are complied.

\section{References}

1. O.A. Korol, MATEC Web of Conferences. 193, 05057 (2018). https://doi.org/10.1051/matecconf/201819305057

2. O. Korol, A. Dudina, IOP Conference Series: Materials Science and Engineering, 661, 012088 (2019).

3. O. Korol, A. Dudina, E3S Web of Conferences. 97, 06027 (2019). https://doi.org/10.1051/e3sconf/20199706027

4. O. Korol, Y. Kustikova, E3S Web of Conferences. 33, 03070 (2018). https://doi.org/10.1051/e3sconf/20183303070

5. L.R. Mailyan, Matec web of conferences. SPBWOSCE-2016, 106, 04010 (2017). DOI: $10.1051 /$ ma-tecconf $/ 201710604010$

6. L.R. Mailyan, Matec web of conferences. SPBWOSCE-2016, 106, 04011 (2017). DOI:10.1051/ ma-tecconf/201710604011

7. E. Lyapuntsova, I. Belozerova, I. Drozdova, O. Korol, E3S Web of Conferences. 97, 06034 (2019). https://doi.org/10.1051/e3sconf/20199706034

8. E. Korol, N. Shushunova, Procedia Engineering, 161, 1820-1826 (2016).

9. E. Korol, N. Shushunova, Procedia Engineering, 153, 287-291 (2016).

10. E. Korol, N. Shushunova, S. Rerikh, E3S Web of Conferences 97, 06023 (2019). https://doi.org/10.1051/e3sconf/20199706023

11. O. Korol, N. Shushunova, D. Lopatkin, A. Zanin, T. Shushunova, MATEC Web of Conferences 251, 06002 (2018). DOI: 10.1051/matecconf/201825106002

12. E. Korol, N. Shushunova, MATEC Web of Conferences Cep. "International Science Conference SPbWOSCE-2016 "SMART City"' 06014 (2017).

13. S. Korol, Shushunova, N., Shushunova, T. Indicators of the resource efficiency development in Russia, MATEC Web of Conferences 193, 05075 (2018). DOI: 10.1051/matecconf/201819305075

14. Korol, E., N. Shushunova, IOP Conference Series Materials Science and Engineering 471, 08201 (2019). DOI: 10.1088/1757-899X/471/8/082011

15. V.G. Borkovskaya, Journal MATEC Web of Conferences, 251, 06025 (2018). DOI: https://doi.org/10.1051/matecconf/201825106025

16. V. Borkovskaya, D. Passmore, MATEC Web of Conf., 193, 05027 (2018). DOI: https://doi.org/10.1051/matecconf/201819305026

17. V.O. Evseev, V.G. Borkovskaya, R. Barkhi, IOP Conf. Series: Journal of Physics: Conf. Series 1425, 012175 (2020). doi:10.1088/1742-6596/1425/1/012175

18. D. Passmore, V.G. Borkovskaya, IOP Conf. Series: Journal of Physics: Conf. Series 1425, 012166 (2020). doi:10.1088/1742-6596/1425/1/012166 
19. V.G. Borkovskaya, D. Passmore, Smart Technologies and Innovations in Design for Control of Technological Processes and Objects: Economy and Production. SIST 138, 24 (Chapter. FarEastCon, 2018). DOI:10.1007/978-3-030-15577-3_24

20. V.G. Borkovskaya, Advanced Materials Research. Manufacturing Management and Engineering Management, 945-949(22) 3012-3015 (2014). DOI: 10.4028/www.scientific.net/AMR.945-949.3012

21. E. Korol, O. Korol, E3S Web of Conferences, 33, 02076 (2018). DOI: $10.1051 / \mathrm{e} 3$ sconf $/ 20183302076$ 